\title{
Achieving Results in MBA Communication
}

\section{Deborah J. Barrett}

Rice University, Houston, Texas

FOR THE COMMUNICATION PROGRAM at Rice University's Jones Graduate School of Management, we have established the following as our mission:

- to provide the instruction, guidance, and resources for students to improve their oral, written, and interpersonal communication skills

- to ensure students possess the knowledge and confidence in individual and team communication to assume future organizational leadership roles.

How we achieve this mission is the focus of this article. After a brief overview of the program, I discuss three keys to the success of the program: individual coaching, integrated team instruction, and constant assessment of the students and the program. Although in place only four years, the program has been judged a success by the students, faculty, administration, and business community. The program accomplishes its mission and achieves the desired results producing MBAs with strong leadership communication ability.

\section{An Overview of the Program}

The Rice MBA communication program started in the fall of 1998 with three principles at its core: (1) individual instruction and coaching tailored to each student's assessed needs; (2) practical, team-based coaching and communication instruction related to integrated core course assignments; (3) minimal group instruction with case discussion on major communication topics, such as strategy, presentations, business writing, and team management.

The communication program begins in pre-term with assessments and some instruction, climaxes in the fall semester with a 15-week course, and continues with project-specific communication and team coaching in the Action Learning Project (ALP), 
ten-week student team projects to solve real business problems for companies in the area in the spring semester (Exhibit 1).

Exhibit 1. The Jones School MBA Communication Program Framework

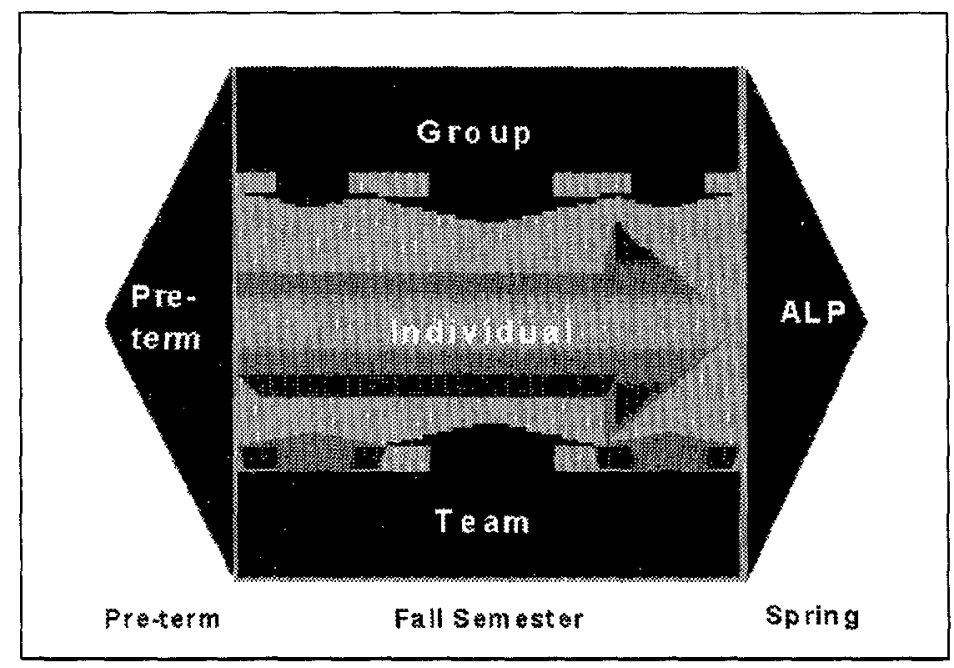

In the program, the students work on the basic skills of writing, speaking, and listening, as well as on management level skills, including team and meeting management, non-verbal and intercultural variables, and communication ethics. Throughout, the program prepares them to think strategically about communication so that they have the ability to analyze an audience, tailor their messages, and employ the most effective medium. Thus, although the MBA communication program at Rice emphasizes the development of basic skills, it also focuses on the more advanced strategic skills necessary for the students to be future organizational leaders.

\section{Criteria for Success}

The program balances individual, team, and group instruction; however, the individual skill development and the integrated team 
instruction, combined with the frequent and constant measurement of the program and the students, make the program a success.

\section{Indlvidual SkIII Development}

Individual instruction is the heart of our communication program. MBAs come in with very diverse experiences and communication abilities; thus, a one-size-fits-all approach to communication instruction will not allow the much-needed individual tailoring to meet their needs. We have, therefore, created a highly individualized program that contains the following:

- profile of the student's communication experiences and ability completed by each student online before pre-term

- pre-term assessments consisting of a usage assessment targeting the most common errors in business writing, a case-based writing assessment designed to test their ability to analyze an audience and write an effective letter, and a taped, threeminute impromptu presentation

- a meeting with the communication faculty to review all of the assessments and to begin developing the communication development plan (CDP)

- individual tutoring and coaching throughout the fall semester

- communication workshops consisting of no more than 15 students

- a post-assessment (final exam) to determine improvement and basic skills mastery.

Starting with the first meeting with the instructor during pre-term, students begin to accept the responsibility for designing their own individual communication development program through their CDPs. We provide a CDP template that calls for the students to summarize their strengths and weaknesses, establish their communication improvement objectives, define their level of expected improvement, and determine their proposed improvement approach and timetable. Students turn in their CDPs to the communication faculty, and we review them and return them with comments. The students then use the 
CDP to guide their communication improvement activities all semester.

In addition to the one-on-one coaching they receive from the communication faculty, students can attend small group workshops in oral presentations, writing, and grammar offered throughout the fall semester as well as participate in the Toastmasters Club, formed and managed by the students. Also, any students needing assistance with pronunciation can work with a diction coach.

At the end of the fall semester, the communication faculty measure the student's overall communication improvement in a final oral presentation, case writing assignment, and usage assessment. The students receive a grade for the final exam, but we also award a grade for class participation, which includes their effort in reaching their improvement targets. The students also assess their own progress in our end-of-semester evaluations discussed below.

\section{Cross-course integrated Team Instruction}

Another key element of our success is the team instruction, which is based on integrated team assignments and on the communication faculty providing team instruction and coaching. The communication faculty teach team problem solving, meeting management, and project management. In addition, we establish forums for team presentation practice sessions, providing feedback to the teams on the structure, PowerPoint design, and delivery of their presentations.

Students work in teams on a variety of communication assignments that are integrated with other core curriculum courses. For example, a team presentation and team report are required as a major marketing assignment, with evaluations by both the marketing and communication faculty. The marketing professor defines the assignment topic and sets the parameters for the assignment. Both professors attend the presentation and grade the final report. In addition to the presentation and report, the communication faculty build team management, presentation practice, and team evaluations into this assignment.

The students like this combined assignment. When asked if they would recommend keeping the assignment as part of the 
communication class, 92.8 percent said, "Yes." By the communication faculty using the team projects from other classes, we leverage the student's other class work. The combined team assignments demonstrate how integral communication is to business topics and how essential good team communication skills are to solving and presenting on business problems.

\section{Student and Program Measurement}

The third key component that leads to our success is the constant assessment of the program and the students. Every year we survey the first-year MBAs before they enter the program and at the end of the fall semester. The end-of-semester survey helps us know if we need to make changes in our instruction, and it measures how much the students are improving. The most important question we ask at the end of the fall semester is, "Have your communication skills improved as a result of the class?" The average for the past four years is 86 percent of the students reporting overall improvement in their individual communication skills in response to this question.

When we compare the profile data to the end-of-semester survey, we find that the students report substantial improvement on specific communication competencies each year. Across all four years, an average of 75 percent of the students ranked their proficiency as either high or moderately high, compared to their original self-assessment during pre-term on topics such as the following:

- delivering individual and team presentations

- conducting audience analysis

- working in project teams

- creating PowerPoint presentations

- writing documents, such as letters, memos, and executive summaries.

In addition to self-assessing their improvement, we ask them to evaluate the content and structure of the course by asking them which of the subject areas or activities they would like us to "keep," "modify," or "omit." We then use this information to make 
adjustments to the core course in the fall of the next year. For example, in individual instruction in 2001, almost 95 percent of students wanted to keep the one-on-one faculty meetings and the establishment of individual communication development plans. They also liked the individual workshops, with 97 percent of them requesting the same or a higher level of workshop opportunities. In addition, they wanted to keep the communication faculty's role in team coaching, with approximately 85 percent of students expressing a desire to keep or increase the communication faculty's team coaching role.

The constant evaluation is one way to ensure we adjust to the students' changing needs year after year. The Jones Graduate School of Management MBA communication program started strong and has evolved over its first four years into an even more effective program, but we know we can always be better. The program yields positive results in improving the students' skills and in preparing them to assume leadership roles upon completing their MBAs. Thus, we feel confident in saying the program achieves its intended results.

Address correspondence to the author, Jones Graduate School of Management, Rice University, Houston TX 77005-1892 (e-mail: barrett@rice.edu). 
Copyright of Business Communication Quarterly is the property of Association for Business Communication and its content may not be copied or emailed to multiple sites or posted to a listserv without the copyright holder's express written permission. However, users may print, download, or email articles for individual use. 